\title{
Bid-overexpression regulates proliferation and phosphorylation of Akt and MAPKs in response to etoposide-induced DNA damage in hepatocellular carcinoma cells
}

\author{
This article was published in the following Dove Press journal: \\ OncoTargets and Therapy \\ 16 October 2012 \\ Number of times this article has been viewed
}

\author{
Yuanyue $\mathrm{Li}^{\prime}$ \\ Congjie $\mathrm{Dai}^{2}$ \\ Juan $\mathrm{Li}^{3}$ \\ Weiwei Wang ${ }^{3}$ \\ Gang Song ${ }^{3}$ \\ 'Fisheries College, Jimei University, \\ Fujian, China; ${ }^{2}$ School of Chemical \\ and Life Science, Quanzhou Normal \\ University, Fujian, China; ${ }^{3} \mathrm{Cancer}$ \\ Research Center, Medical College \\ of Xiamen University, Xiamen, China
}

Correspondence: Gang Song

Cancer Research Center,

Medical College of Xiamen University,

Xiamen 361005, China

Tel +86592 2188275

Fax +86 592218673 I

Email gangsongsd@xmu.edu.cn
Background: Growing evidence supports BH3-interacting domain death agonist (Bid) playing a dual role in DNA damage response. However, the effects of Bid on hepatocellular carcinoma (HCC) cell proliferation in response to etoposide-induced DNA damage have not been sufficiently investigated.

Methods: Using a stable Bid-overexpression HCC cell line, Bid/PLC/PRF/5, overexpression of Bid promoted loss of viability in response to etoposide-induced DNA damage. MTT [3-(4,5-dimethylthiazol-2-yl)-2,5-diphenyltetrazolium bromide]- and BrdU (5'-bromo-2'deoxyuridine)-labeling assays revealed that etoposide-inhibited HCC cells grew in concentrationand time-dependent manners. The phosphorylations of Akt and mitogen-activated protein kinases (MAPKs) in response to etoposide-induced DNA damage were analyzed by Western blotting.

Results: The survival rates of $100 \mu \mathrm{M}$ etoposide on the cells with control vector and Bid/ $\mathrm{PLC} / \mathrm{PRF} / 5$ at 48 hours amounted to $71 \% \pm 0.75 \%$ and $59 \% \pm 0.60 \%$ with MTT assay, and similar results of $85 \% \pm 0.08 \%$ and $63 \% \pm 0.14 \%$ with BrdU-labeling assay respectively. Moreover, overexpression of Bid sensitized the cells to apoptosis at a high dose of etoposide (causing irreparable damage). However, it had little effect on the proliferation at a low dose of etoposide (repairable damage). Furthermore, the phosphorylation status of Akt and MAPKs were investigated. Overexpression of Bid suppressed the activation of Akt with respect to etoposideinduced DNA damage. Similar to Akt, the levels of phosphorylated p38 and phosphorylated c-Jun were attenuated by Bid-overexpression. On the contrary, the level of phosphorylated ERK1/2 was sustained at a high level, especially in Bid/PLC/PRF/5 cells.

Conclusion: Taken together, these results suggest that overexpression of Bid suppressed the activation of Akt, p38, and c-Jun, and promoted the activation of ERK1/2 induced by etoposide, suggesting that the promotion of ERK1/2 activation may have a negative effect on Bid-mediated HCC DNA damage induced by etoposide.

Keywords: HCC, mitogen-activated protein kinases, BH3-interacting domain death agonist

\section{Background}

$\mathrm{BH} 3$-interacting domain death agonist (Bid), a $\mathrm{BH} 3$ domain-only pro-apoptotic molecule, is initially found to be cleaved by caspase- 8 in response to death receptormediated apoptotic signaling. ${ }^{1,2}$ The truncated $\mathrm{Bid}$ (tBid) is modified by myristoylation and translocated into mitochondria where it activates oligomerization of Bak or Bax and induces cytochrome $\mathrm{c}$ release. Cytochrome $\mathrm{c}$ in turn activates the apoptotic cascade 
of caspase-9 and -3, leading to cell death. ${ }^{3,4}$ Findings from the present authors and others have shown that the cleavage of Bid may not be an absolute requirement for Bid to be pro-apoptotic..$^{5-8}$ Moreover, upon the administration of a high dose of DNA double-strand break agent causing irreparable damage to hepatocellular carcinoma (HCC), Bid is quickly translocated to the mitochondria to release cytochrome c. ${ }^{9}$ Thus, it can be seen that the Bid-mediated mitochondrial pathway is critical to apoptotic cell death initiated by external signals from other cells or by internal warnings resulting from cellular stresses.

In addition to facilitating apoptosis with respect to DNA damage, Bid also promotes DNA repair. Upon DNA damage by stimulants such as etoposide or irradiation, DNA damage kinase ATM (ataxia telangiectasia mutated) is activated by phosphorylation, which in turn phosphorylates Bid at serine 61 or serine 78. Phosphorylated Bid participates in cell-cycle arrest and DNA repair. ${ }^{10,11}$ The pro-apoptotic function of full-length Bid might be affected by such phosphorylation, as it facilitates apoptosis to a lesser extent compared with its truncated form, tBid. However, the functions of Bid with respect to DNA-damage response are controversial. ${ }^{12}$ Furthermore, recent studies have also demonstrated that the physiological role of Bid in development and cellular homeostasis may be cell-type specific. For example, mice lacking Bid do not enhance tumorigenesis and development of liver cancers following the administration of a chemical carcinogen, diethylnitrosamine (DEN). On the contrary, their tumor development is delayed, ${ }^{13}$ which could be better explained by the role of Bid in promoting cell proliferation.

Akt and mitogen-activated protein kinase (MAPK) pathways play very important roles in response to extracellular stimuli to regulate several cellular functions including cell proliferation, apoptosis, and survival. ${ }^{14,15}$ The authors of this present study therefore analyzed the phosphorylation status of Akt and MAPKs with respect to etoposide-induced DNA damage of human HCC cells. As etoposide has been reported to activate Akt and ERK signaling pathways in human gastric cancer cells, ${ }^{16}$ this study attempted to determine whether etoposide can activate Akt and MAPKs pathways in human HCC cells.

HCC remains one of the most difficult tumors to treat, especially when the tumor is advanced or unresectable. Since there is only a narrow understanding of the molecular, cellular, and environmental mechanisms that drive its disease pathogenesis, there are only limited therapeutic options. ${ }^{17}$ Previous studies have shown that overexpression of $\mathrm{Bid} / \mathrm{tBid}$ on $\mathrm{HCC}$ cells increase the sensitivity towards chemotherapeutic agents such as staurosporine, camptothecin, 5-fluorouracil (5-FU), doxorubicin (Dox), and etoposide. ${ }^{8,9,18,19}$ Furthermore, the authors of this present study revealed a novel p53 nucleocytoplasmic shutting function, which plays an important role in assisting Bid translocation from the nucleus to the cytoplasm through interaction with Bid following the stimulation of etoposide. ${ }^{8}$

In the present study, using a stable Bid-overexpression $\mathrm{HCC}$ cell line, Bid/PLC/PRF/5, the effect of Bid-overexpression on the HCC cellular proliferation in response to etoposideinduced DNA damage was examined. The study suggested that overexpression of Bid in HCC cells promoted loss of viability likely through regulating Akt and MAPKs signaling pathways, suggesting Bid could potentially provide a therapeutic option that combines cytotoxic therapy for human HCC.

\section{Materials and methods Reagents and antibodies}

Etoposide was purchased from Calbiochem (USA). MTT [3-(4, 5-dimethylthiazol-2-yl)-2, 5-diphenyltetrazolium bromide] and protease inhibitor cocktail were purchased from Sigma-Aldrich (St Louis, MO). The enhanced chemiluminescence (ECL ${ }^{\mathrm{TM}}$ ) detection system from Amersham Biosciences, Inc (Freiburg, Germany). Protein assay kit for protein quantity analysis was purchased from Bio-Rad Laboratories (Hercules, CA). Lipofectamine 2000 and G418 were purchased from Life Technologies (Carlsbad, CA). The rabbit anti-Bid, anti-actin, anti-phospho-Akt $\left(\mathrm{S}_{473}\right.$ and $\left.\mathrm{T}_{308}\right)$, anti-Akt, anti-rabbit IgG, and anti-mouse IgG antibodies were provided by Santa Cruz Biotechnology, Inc (Santa Cruz, CA). Mouse anti-phospho-ERK1/2, rabbit anti-ERK1/2, anti-phospho-p38, anti-p38, anti-phospho-c-Jun, and anti-c-Jun were purchased from Cell Signaling Technology (Danvers, MA). All other reagents were of analytical reagent quality.

\section{Cell culture and generation of Bid-producing HCC cells}

The human hepatocellular carcinoma cell line PLC/PRF/5 was obtained from American Type Culture Collection (Manassas, VA), and was cultured as previously described..$^{89}$ The construction of Bid/pcDNA3.1 expression plasmid or empty vector was introduced into PLC/PRF/5 cells, and the stable cell clones were obtained by the addition of $500 \mu \mathrm{g} / \mathrm{mL}$ of G418 into the culture medium. The transfection, selection, and culture of the stable cell clones of Bid/PLC/PRF/5 and Vec/PLC/PRF/5 were carried out essentially as previously described. ${ }^{9}$ 


\section{MTT assay}

The cell viability was measured by MTT method as previously described. ${ }^{20}$

\section{Brd-U-labeling proliferation assay}

Cell proliferation in response to etoposide was confirmed by $5^{\prime}$-bromo-2'-deoxyuridine (Brd-U) incorporation method using an enzyme-linked immunosorbent assay kit procured from Roche Diagnostics Corp (Indianapolis, IN). Briefly, cells were treated in a similar manner as described for the cell viability assay, in 96-well microtiter plates. Six hours prior to the end of the interval of measurement, Brd-U $(10 \mu \mathrm{M})$ was added. The cells were fixed, lysed, and then treated for 3 minutes at $37^{\circ} \mathrm{C}$ with peroxidase-conjugated, anti-Brd-U antibody supplied by the manufacturer. The cells were washed three times followed by the addition of substrate solution. Absorbance was measured at $405 \mathrm{~nm}$, with a reference wavelength at $490 \mathrm{~nm}$.

\section{Western blot analysis}

Western blot was performed as reported previously. ${ }^{20,21} \mathrm{After}$ harvesting, the experimental cells were washed and lysed in lysis buffer. The total lysate was mixed with loading buffer, and preheated at $95^{\circ} \mathrm{C}$ for 10 minutes, then loaded onto sodium dodecyl sulfate-polyacrylamine gel. The proteins were transferred onto polyvinylidene fluoride membrane and blocked in 5\% milk, and then incubated for 1 hour or overnight at $4^{\circ} \mathrm{C}$ with primary antibody. After hybridization with primary antibody, the membrane was washed and incubated with horseradish peroxidase-labeled secondary antibody. Final detection was performed with ECL Western blotting reagents. The blot was then stripped at $50^{\circ} \mathrm{C}$ for 30 minutes. The membranes were re-blotted for detection of other proteins after extensive wash.

\section{Statistic analysis}

The data are presented as the mean \pm standard deviation for at least three separate determinations for each group. The differences between the groups were examined for statistical significance using the Student's $t$-test with SPSS Statistics (IBM Corporation, Somers, NY) software.

\section{Results}

\section{Generation and proliferative characteristics of Bid-producing HCC cells}

A previous study showed that the expression of Bid in well and moderately differentiated HCC was lower than in the corresponding nontumorous tissues from the same patient, whereas the Bid expression was notably enhanced in tumorous liver tissues from patients with poorly differentiated tumors. ${ }^{22}$ To further assess the functional significance of Bid expression during the development of $\mathrm{HCC}$, it was investigated whether stable overexpression of Bid in human HCC cells could alter cell survival in vitro. To this end, a human HCC cell line PLC/PRF/5 was selected since it expresses a low level of endogenous Bid (Figure 1A, left two lanes). Bid DNA construct was transfected into the $\mathrm{PLC} / \mathrm{PRF} / 5$ cells, and after drug selection, stable cell clones were isolated and verified for Bid expression. The expression of Bid in selected clones was verified with specific antibody against Bid (Figure 1A, right two lanes). Overexpression of $\mathrm{Bid}$ in $\mathrm{PLC} / \mathrm{PRF} / 5$ cells led to an obvious morphological change with an appearance of fibroblast-like cell shape (data not shown), and such a change did not result in an alteration in the rate of cell proliferation under $10 \%$ serum conditions in vitro (Figure 1B). However, Bid-producing $\mathrm{PLC} / \mathrm{PRF} / 5$ cells led to a significant $(P<0.05)$ reduction in cell proliferation rate under serum-depleted conditions (Figure 1C). These observations suggest that Bid could act to decrease cellular survival for HCC cells by serum starvationinduced cellular stress responses.

\section{Bid promoted loss of viability in response to etoposide-induced DNA damage}

A previous study showed that Bid sensitized apoptosis induced by chemotherapeutic drugs such as staurosporine, camptothecin, 5-FU, and Dox in human HCC cells. ${ }^{18}$ In this study, two methods were used to further explore the effect of Bid-overexpression on human HCC cell viability in response to etoposide-induced DNA damage. First, cell viability was determined by the MTT assay method. As shown in Figure 2A and B, etoposide inhibited the HCC cells growth in a concentration- and time-dependent manner. A significant loss of viability was detected in the cells treated with $100 \mu \mathrm{M}$ or more etoposide for 48 hours. The cell survival rates of $100 \mu \mathrm{M}$ etoposide on the cells with control vector (Figure 2A) and the cells with Bid/PLC/ $\mathrm{PRF} / 5$ (Figure 2B) at 48 hours amounted to $71 \% \pm 0.75 \%$ and $59 \% \pm 0.60 \%$ respectively. The cell proliferation rate was further examined by the BrdU-labeling assay method. Similar results to the MTT assay were observed. At $100 \mu \mathrm{M}$ etoposide for 48 hours treatment, the proliferation rates of the cells with control vector and the cells with $\mathrm{Bid} /$ PLC/PRF/ 5 amounted to $85 \% \pm 0.08 \%$ and $63 \% \pm 0.14 \%$ respectively (Figure $2 \mathrm{C})(P<0.05)$. All these results indicate 
A

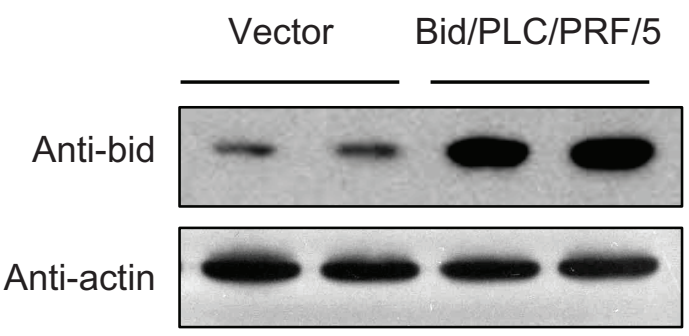

B

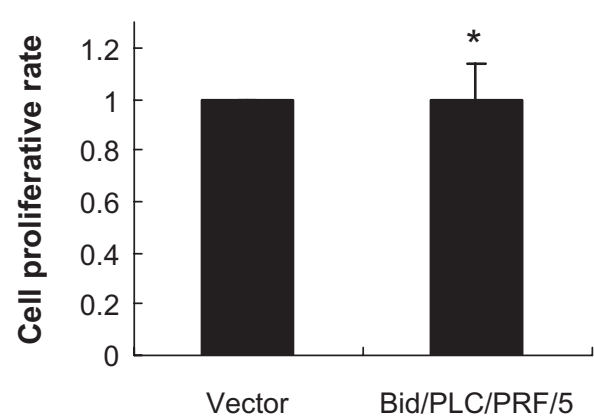

C

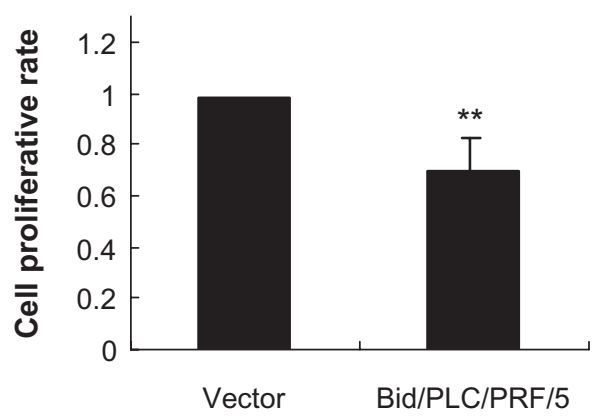

Figure I Proliferative characteristic of Bid-overexpressing PLC/PRF/5 clones and vector control clones. (A) Analysis of Bid-overexpressing PLC/PRF/5 clones and vector control clones by Western blot. (B and $\mathbf{C}$ ) The proliferation analysis of cell viability with MTT assay under $10 \%$ serum or serum starvation conditions.

Notes: $D$ ata are reported as means \pm standard deviations of three independent experiments; *indicates $P>0.05$; **indicates $P<0.05$ compared with vector control. Abbreviations: Bid, BH3-interacting domain death agonist; MTT, 3-(4,5-dimethylthiazol-2-yl)-2,5-diphenyltetrazolium bromide.

that overexpression of Bid sensitized the cells to the high concentrations of etoposide treatment. However, it has little effect on the proliferation of the cells treated with low concentrations of etoposide.

\section{Effects of Bid on the activation of Akt in response to etoposide}

Akt and MAPKs signaling pathways are thought to be the pivotal mechanisms of apoptotic signals in malignant cells. ${ }^{14,15}$ Several extracellular stimuli have been shown to activate Akt and MAPKs via phosphorylation. The phosphorylation status of Akt and MAPKs was therefore analyzed with respect to etoposide-induced DNA damage of the human HCC cells. As shown in Figure 3, a significant degree of Akt activation was detected using the phosphor-specific Akt (Ser473 and Thr308) antibodies. An increase in phosphorylated Akt occurred at 2 hours after treatment. The maximal level of phosphorylated Akt was recorded at 12 hours after treatment in the cells with Bid overexpression (Figure 3B). At 48 hour after treatment, the levels of phosphorylated Akt gradually declined to the basal level. Moreover, it was observed that the level of phosphorylated Akt in $\mathrm{Bid} / \mathrm{PLC} / \mathrm{PRF} / 5$ cells was lower than that in the control cells (Figure 3C). This result indicates that the overexpression of Bid can suppress the activation of Akt.

\section{Effects of Bid on the activation of MAPKs in response to etoposide}

MAPKs can be activated by several different anticancer drugs. However, their roles in Bid-mediated apoptosis following etoposide treatment remain unclear. The effects of phosphorylated MAPKs in Bid-mediated apoptosis in human HCC cells (Figures 4-6) were therefore determined. Similar to the result of the phosphorylated Akt observed (Figure 3), the levels of phosphorylated p38 (Figure 4) and phosphorylated c-Jun (Figure 5) were increased in both control vector cells and Bid/PLC/PRF/5 cells. Maximal level of both was detected during the 2-6 hour posttreatment time period, and they gradually declined towards the basal level thereafter. Interestingly, an obvious increase in the phosphorylated ERK was not observed in HCC cells treated with etoposide (Figure 6). On the contrary, the level of phosphorylated ERK1/2 was sustained at a higher level, especially in $\mathrm{Bid} / \mathrm{PLC} / \mathrm{PRF} / 5$ cells. However, after 24 hours of treatment, the level of phosphorylated ERK declined (Figure 6C).

\section{Discussion}

HCC is the fifth most frequent primary malignant tumor worldwide, particularly in parts of Asia and Africa, and the fourth in annual mortality, causing approximately half a 
A

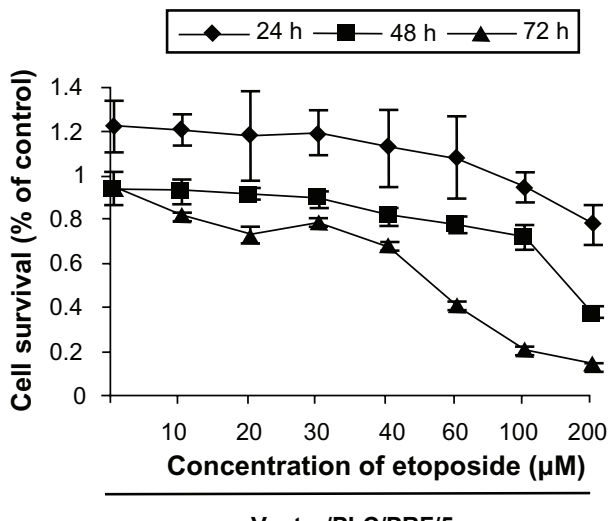

Vector/PLC/PRF/5
B

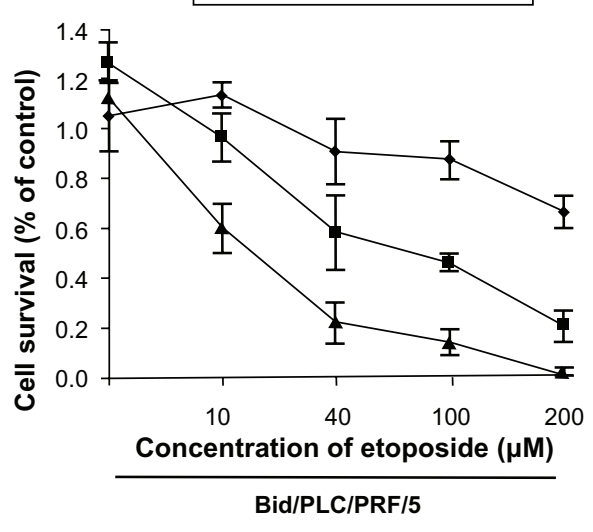

C

Vector/PLC/PRF/5 $\square$ Bid/PLC/PRF/5

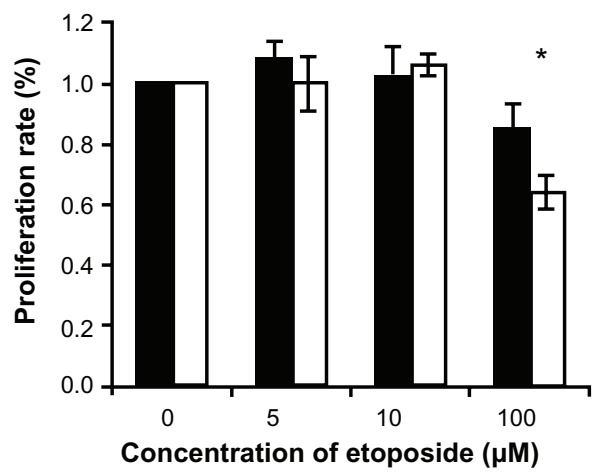

Figure 2 Effect of Bid on the PLC/PRF/5 cell viability in the response of etoposide-induced DNA damage. Overexpression of Bid does not alter the rate of cell proliferation under low concentration of etoposide, but Bid-overexpression cells sensitize apoptosis induced by high concentration of etoposide. (A and B) Cell viability was determined by the MTT assay method. (C) Cell proliferation rate was determined by the BrdU-labeling method assay.

Notes: Data are reported as means \pm standard deviations of three independent experiments; *indicates $P<0.05$ compared with vector control.

Abbreviations: Bid, BH3-interacting domain death agonist; BrdU, 5'-bromo-2'-deoxyuridine; MTT, 3-(4,5-dimethylthiazol-2-yl)-2,5-diphenyltetrazolium bromide.

million deaths each year. ${ }^{23}$ Recently, the rising rate of $\mathrm{HCC}$ has been found in some Western countries. ${ }^{24}$ In addition, the liver is the most frequent site of metastasis, especially from gastrointestinal cancers. Despite its significance, there is only a narrow understanding of the molecular, cellular, and environmental mechanisms that drive disease pathogenesis, and there are only limited therapeutic options. ${ }^{17} \mathrm{HCC}$ remains one of the most difficult tumors to treat, especially when the tumor is advanced or unresectable. Therefore, it is important to develop an efficient treatment for HCC. In this study, Bid was chosen as a potentially therapeutic target that combines cytotoxic therapy for human HCC.

It is well known that the $\mathrm{BH} 3$-only pro-apoptotic member, full-length Bid, and its tBid link the extrinsic death receptor pathway and intrinsic mitochondrial apoptotic pathway. ${ }^{2}$ Etoposide, a well known DNA-damaging agent, is a topoisomerase II inhibitor that has been widely used in several model studies to couple DNA damage with apoptosis. ${ }^{25}$ Exposure to DNA-damaging agents can cause mutations, developmental abnormalities, or cancer. Cells respond to the presence of DNA damage by activating cell cycle checkpoints and repair mechanisms, and a small part of the cells that cannot be repaired are directed towards the apoptotic pathway, ultimately the damaged cells are eliminated through apoptosis. Differential expressions and functions of several Bcl-2 family members in human $\mathrm{HCC}$ have been recently reported, and they were shown to be associated with the effects of anticancer stimuli. ${ }^{26}$ However, Bid, as an abundant pro-apoptotic protein of the Bcl-2 family, its functions and molecular mechanisms in the progression of human HCC are still not well understood, especially in terms of the response of $\mathrm{HCC}$ cells to DNA damage. 
A

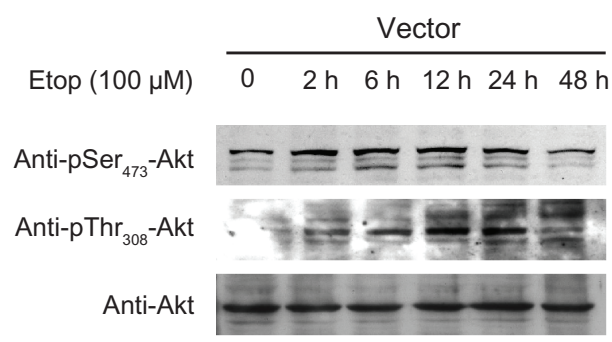

B

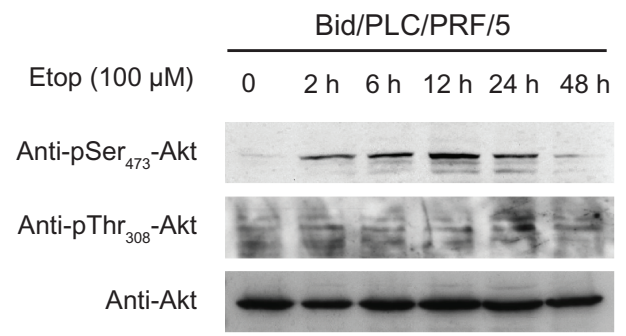

C $\quad \mathrm{pSer}_{473}$-Akt level after etoposide treatment

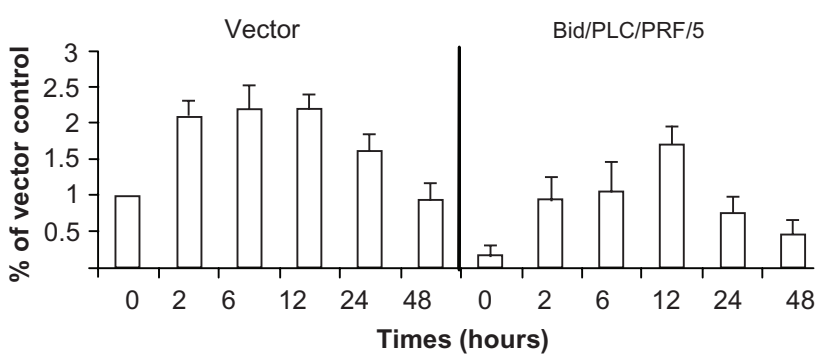

Figure 3 Bid-overexpression on the activation of Akt in response to etoposide. Vector control (A) and Bid/PLC/PRF/5 cells (B) were treated with etoposide for different periods, respectively. Then, p-Akt was detected by Western blot analysis. All blots were subsequently stripped and reprobed with antibodies against Akt. The density of $\mathrm{pSer}_{473}$-Akt protein bands was determined (C).

Abbreviation: Bid, $\mathrm{BH} 3$-interacting domain death agonist.

To further explore the molecular mechanisms of Bidmediated apoptosis of chemotherapeutic drug-induced DNA damage, a previous study showed that overexpression of $\mathrm{Bid} / \mathrm{tBid}$ on HCC cells increase the sensitivity towards chemotherapeutic agents such as staurosporine, camptothecin, 5-FU, and Dox. ${ }^{18}$ The activities of caspase- $8,-9$, and -3 were increased after a 72-hour treatment of 5-FU. Expression level of tBid was also increased due to accumulation of the truncated counterpart. Compared with the full-length Bid, this truncated form could promote higher sensitivity of HCC cells to 5-FU induced cytotoxicity and cytochrome c release, which can be blocked by overexpression of the pro-survival protein Bcl- $\mathrm{x}_{\mathrm{L}}{ }^{18}$ In addition, adenovirus-mediated overexpression of truncated Bid can also reduce cell viability and promote tumor regression in both $\mathrm{p} 53$-sensitive and -resistant $\mathrm{HCC}$ cells. ${ }^{19}$ However, Bid-deficient mice do not have an enhanced development of liver cancers following the administration of
A

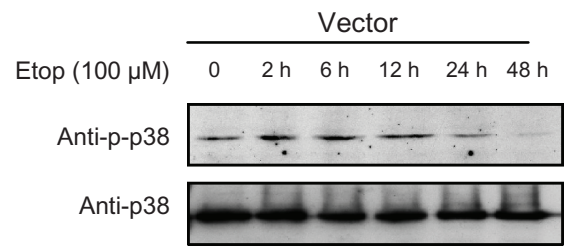

B

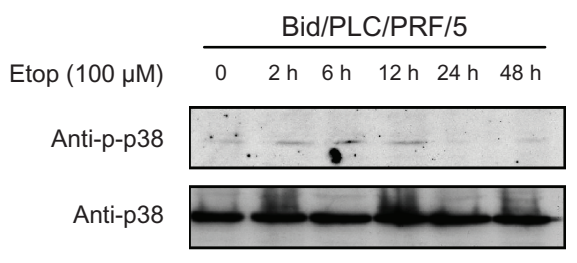

C

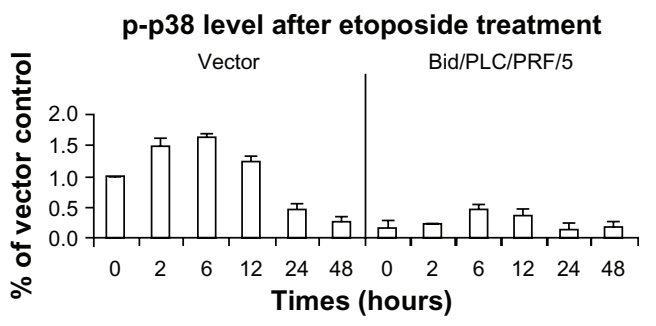

Figure 4 Effects of Bid-overexpression on the phosphorylation of p38 in response to etoposide. Vector control (A) and Bid/PLC/PRF/5 cells (B) were treated with etoposide for different periods of time, respectively. Then P-p38 was detected by Western blot analysis. All blots were subsequently stripped and reprobed with antibodies against $\mathrm{p} 38$. The density of $\mathrm{p}-\mathrm{p} 38$ protein bands was determined (C). Abbreviation: $\mathrm{Bid}, \mathrm{BH} 3$-interacting domain death agonist.

A

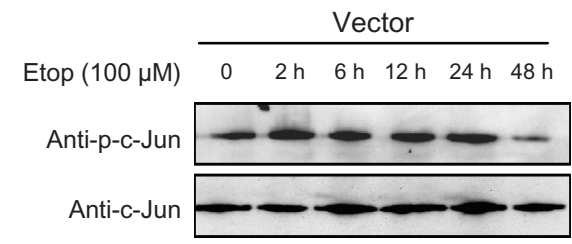

B

$\mathrm{Bid} / \mathrm{PLC} / \mathrm{PRF} / 5$

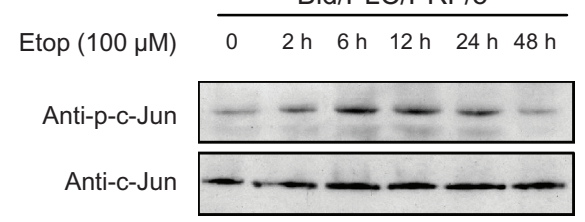

C

p-Jun level after etoposide treatment

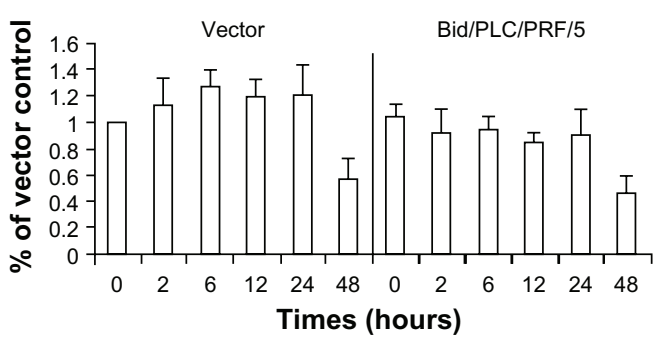

Figure 5 Effects of Bid-overexpression on the phosphorylation of c-Jun in response to etoposide. Vector control (A) and Bid/PLC/PRF/5 cells (B) were treated with etoposide for different periods, respectively. Then, $\mathrm{P}$-c-Jun was detected by Western blot analysis. All blots were subsequently stripped and reprobed with antibodies against c-Jun. The density of p-c-Jun protein bands was determined (C).

Abbreviation: Bid, $\mathrm{BH} 3$-interacting domain death agonist. 
A

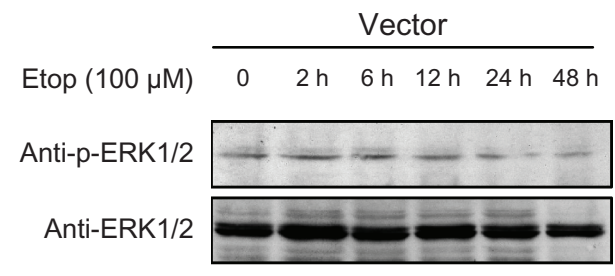

B

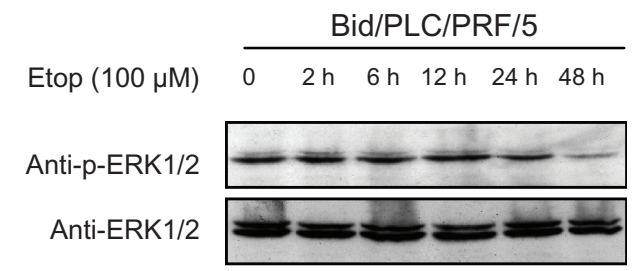

C

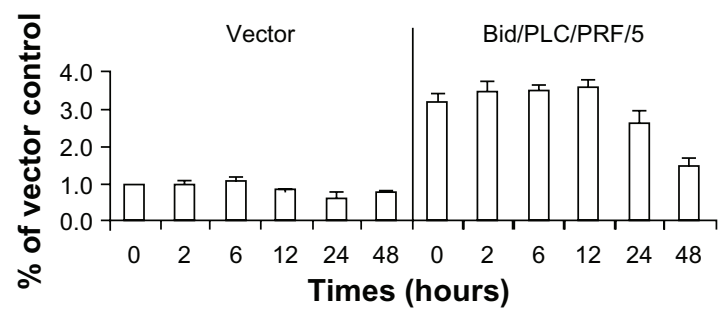

Figure 6 Effects of Bid-overexpression on the phosphorylation of ERKI/2 in response to etoposide. Vector control (A) and Bid/PLC/PRF/5 cells (B) were treated with etoposide for different periods, respectively. Then $\mathrm{p}$-ERKI/2 was detected by Western blot analysis. All blots were subsequently stripped and reprobed with antibodies against ERKI/2. The density of $\mathrm{p}$-ERKI/2 protein bands was determined (C).

Abbreviation: $\mathrm{Bid}, \mathrm{BH} 3$-interacting domain death agonist.

a chemical carcinogen, DEN. On the contrary, Bid-deficient livers show significantly less proliferating cells following DEN administration. ${ }^{13}$ The observations could be better explained by the role of Bid in promoting cell proliferation. In the present investigation, Bid exhibited loss of viability and sensitivity to apoptosis in response to human HCC cells to etoposide-induced DNA damage (Figure 2).

Initiation of apoptosis is the key mechanism following high DNA damage. Recent reports show that Bid will be cleaved and activated after the external stimulus. ${ }^{2} \mathrm{Bid}$, in turn, activates Bax and Bak; both trigger apoptosis. The present study also proposed that Bid-overexpression was more sensitive to etoposide-induced high degree of DNA damage than that of the control. At the molecular level, it has been reported that constitutive activation of Akt and MAPKs signaling pathways by chemotherapy drugs including etoposide promotes resistance to chemotherapy in several cancers. ${ }^{16,27,28}$ The activation of Akt and MAPK signaling pathways are thought to be the pivotal mechanisms of apoptotic signals in malignant cells. To understand the mechanism by which Bid sensitizes HCC cells to apoptosis in response to etoposide-induced DNA damage, the data showed that Bid-overexpression significantly decreased the level of phosphorylated Akt, p38, and c-Jun in HCC cells followed by etoposide-induced DNA damage. Therefore, Bid suppressed the activation of Akt, p38, and c-Jun signaling pathways with the treatment of etoposide, which may be another therapeutic option of chemoresistance in HCC. Bid could promote ERK1/2 phosphorylation, which suggests ERK1/2 activation may have a negative effect on HCC DNA damage induced by etoposide. Furthermore, the levels of Akt and MAPKs phosphorylation decreased gradually to basal levels after 48 hours, and the declinations of Akt and MAPKs phosphorylation in $\mathrm{Bid} / \mathrm{PLC} / \mathrm{PRF} / 5$ cells were coincident with the onset of Bid-overexpression mediated apoptosis. These results again explained that Bid could sensitize apoptosis induced by etoposide.

In summary, the data presented here strongly suggest that Bid-overexpression on human HCC cells promoted loss of viability via mediating different pathways (Akt and MAPKs) in response to different degrees of DNA damage. Elucidation of such intricate mechanisms of the effects of Bid on proliferation could potentially provide a therapeutic option that combines cytotoxic therapy for human HCC.

\section{Acknowledgments}

This work was supported by grants from the National Natural Science Foundation of China (No 31071187, 81272721), the Fundamental Research Funds for the Central Universities (2010121102), Xiamen Municipal Science and Technology Innovation Fund Project (3502Z20114018), and the Program for New Century Excellent Talents in Fujian Province University.

\section{Disclosure}

The authors report no conflicts of interest in this work.

\section{References}

1. Wang K, Yin XM, Chao DT, Milliman CL, Korsmeyer SJ. BID: a novel BH3 domain-only death agonist. Genes Dev. 1996;10(22):2859-2869.

2. Yin XM. Bid, a BH3-only multi-functional molecule, is at the cross road of life and death. Gene. 2006;369:7-19.

3. Li H, Zhu H, Xu CJ, Yuan J. Cleavage of BID by caspase 8 mediates the mitochondrial damage in the Fas pathway of apoptosis. Cell. 1998; 94(4):491-501.

4. Luo X, Budihardjo I, Zou H, Slaughter C, Wang X. Bid, a Bcl2 interacting protein, mediates cytochrome c release from mitochondria in response to activation of cell surface death receptors. Cell. 1998;94(4):481-490.

5. Konig HG, Rehm M, Gudorf D, et al. Full length Bid is sufficient to induce apoptosis of cultured rat hippocampal neurons. BMC Cell Biol. 2007;8:7-14

6. Sarig R, Zaltsman Y, Marcellus RC, Flavell R, Mak TW, Gross A. BIDD59A is a potent inducer of apoptosis in primary embryonic fibroblasts. J Biol Chem. 2003;278(12):10707-10715. 
7. Valentijn AJ, Gilmore AP. Translocation of full-length Bid to mitochondria during anoikis. J Biol Chem. 2004;279(31):32848-32857.

8. Song G, Chen GG, Yun JP, Lai PBS. Association of p53 with Bid induces cell death in response to etoposide treatment in hepatocellular carcinoma. Curr Cancer Drug Targets. 2009;9(7):871-880.

9. Song G, Chen GG, Chau DK, Miao J, Lai PBS. Bid exhibits S phase checkpoint activation and plays a pro-apoptotic role in response to etoposide-induced DNA damage in hepatocellular carcinoma cells. Apoptosis. 2008;13(5):693-701.

10. Zinkel SS, Hurov KE, Ong C, Abtahi FM, Gross A, Korsmeyer SJ. A role for proapoptotic BID in the DNA-damage response. Cell. 2005; 122(4):579-591.

11. Kamer I, Sarig R, Zaltsman Y, et al. Proapoptotic BID is an ATM effector in the DNA-damage response. Cell. 2005;122(4):593-603.

12. Kaufmann T, Tai L, Ekert PG, et al. The BH3-only protein bid is dispensable for DNA damage- and replicative stress-induced apoptosis or cell-cycle arrest. Cell. 2007;129(2):423-433.

13. Bai L, Ni HM, Chen X, Difrancesca D, Yin XM. Deletion of bid impedes cell proliferation and hepatic carcinogenesis. Am J Pathol. 2005;166(5): $1523-1532$.

14. Song G, Ouyang G, Bao S. The activation of Akt/PKB signaling pathway and cell survival. J Cell Mol Med. 2005;9(1):59-71.

15. Kim EK, Choi EJ. Pathological roles of MAPK signaling pathways in human diseases. Biochim Biophys Acta. 2010;1802(4):396-405.

16. Liu SQ, Yu JP, Yu HG, Lv P, Chen HL. Activation of Akt and ERK signalling pathways induced by etoposide confer chemoresistance in gastric cancer cells. Dig Liver Dis. 2006;38(5):310-318.

17. Di Maio M, De Maio E, Perrone F, Pignata S, Daniele B. Hepatocellular carcinoma: systemic treatments. J Clin Gastroenterol. 2002;35(Suppl 2): S109-S114.

18. Miao J, Chen GG, Chun SY, Chak EC, Lai PB. Bid sensitizes apoptosis induced by chemotherapeutic drugs in hepatocellular carcinoma. Int $J$ Oncol. 2004;25(3):651-659.
19. Miao J, Chen GG, Chun SY, et al. Adenovirus-mediated tBid overexpression results in therapeutic effects on p53-resistant hepatocellular carcinoma. Int J Cancer. 2006;119(8):1985-1993.

20. Song G, Ming Y, Mao Y, Bao S, Ouyang G. Osteopontin prevents curcumin-induced apoptosis and promotes survival through Akt activation via $\{$ alpha $\} \mathrm{v}\{$ beta $\}$ integrins in human gastric cancer cells. Exp Biol Med. 2008;233(12):1537-1545.

21. Song G, Ouyang G, Mao YB, Ming YL, Bao S, Hu TH. Osteopontin promotes metastatic growth of gastric cancer by augmenting cell survival and invasion through Akt-mediated HIF- $1 \alpha$ up-regulation and MMP9 activation. $J$ Cell Mol Med. 2009;13(8B):1706-1718.

22. Chen GG, Lai PB, Chak EC, Xu H, Lee KM, Lau WY. Immunohistochemical analysis of pro-apoptotic Bid level in chronic hepatitis, hepatocellular carcinoma and liver metastases. Cancer Lett. 2001;172(1):75-82.

23. Kew MC. Epidemiology of hepatocellular carcinoma. Toxicology. 2002;181-182:35-38.

24. El-Serag HB. Hepatocellular carcinoma: an epidemiologic view. J Clin Gastroenterol. 2002;35(5 Suppl 2):S72-S78.

25. Baldwin EL, Osheroff N. Etoposide, topoisomerase II and cancer. Curr Med Chem Anticancer Agents. 2005;5(4):363-372.

26. Farazi PA, DePinho RA. Hepatocellular carcinoma pathogenesis: from genes to environment. Nat Rev Cancer. 2006;6(9):674-687.

27. Clark AS, West K, Streicher S, Dennis PA. Constitutive and inducible Akt activity promotes resistance to chemotherapy, trastuzumab, or tamoxifen in breast cancer cells. Mol Cancer Ther. 2002;1(9): 707-717.

28. Kraus AC, Ferber I, Bachmann SO, et al. In vitro chemo- and radioresistance in small cell lung cancer correlates with cell adhesion and constitutive activation of AKT and MAP kinase pathways. Oncogene. 2002;21(57):8683-8695.
OncoTargets and Therapy

\section{Publish your work in this journal}

OncoTargets and Therapy is an international, peer-reviewed, open access journal focusing on the pathological basis of all cancers, potential targets for therapy and treatment protocols employed to improve the management of cancer patients. The journal also focuses on the impact of management programs and new therapeutic agents and protocols on

\section{Dovepress}

patient perspectives such as quality of life, adherence and satisfaction The manuscript management system is completely online and includes a very quick and fair peer-review system, which is all easy to use. Visit http://www.dovepress.com/testimonials.php to read real quotes from published authors. 